\title{
Electron-Collision-Induced Dissociative Ionization Cross Sections for Silane
}

\author{
Satyendra Pal, ${ }^{1,2}$ Neeraj Kumar, ${ }^{1}$ and Anshu ${ }^{1}$ \\ ${ }^{1}$ Department of Physics, Janta Vedic College, Baraut-250 611 (Baghpat), India \\ ${ }^{2}$ Department of Physics, M.M.H. College, Ghaziabad-201001 (UP), India
}

Correspondence should be addressed to Satyendra Pal, s.pal@india.com

Received 8 September 2008; Accepted 12 February 2009

Recommended by Frantisek Tureček

Secondary electron energy and angle dependent differential cross sections for the production of cations $\mathrm{SiH}_{n}{ }^{+}(n=0-3), \mathrm{H}_{2}{ }^{+}$and $\mathrm{H}^{+}$resulting from dissociative ionization of $\mathrm{SiH}_{4}$ by electron collision have been evaluated at fixed incident electron energies of 100 and $200 \mathrm{eV}$. The semiempirical formulation of Jain and Khare which requires the oscillator strength data as a major input has been employed. In the absence of experimental data for differential cross sections, the corresponding derived integral partial and total ionization cross sections in the energy range varying from ionization threshold to $1000 \mathrm{eV}$ revealed a satisfactory agreement with the available experimental and theoretical data. We have also evaluated the ionization rate coefficients on the basis of calculated partial ionization cross sections and Maxwell-Boltzmann energy distributions.

Copyright (c) 2009 Satyendra Pal et al. This is an open access article distributed under the Creative Commons Attribution License, which permits unrestricted use, distribution, and reproduction in any medium, provided the original work is properly cited.

\section{Introduction}

This work is a part of our project on electron impact ionization on technological molecules in low-energy regimes. Our aim is to determine the differential and integral cross sections corresponding to the production of molecular and atomic cations in electron impact ionization of the $\mathrm{SiH}_{4}$ molecule, which is widely used in plasma deposition of silicon containing thin films. Electron ionization cross sections of $\mathrm{SiH}_{4}$ are needed for the modeling of charge carrier balance in plasma and gas phase media $[1,2]$. There is dearth to elucidate the atomic and molecular properties and their interaction with photons and electrons. Photoabsorption and photoionization studies of silane and its radicals have already been made by Gallagher et al. [3], Johnson III et al. [4], and Cooper et al. [5, 6]. The experimental determination of partial and total electron ionization cross sections includes those of Perrin et al. [7], Chatham et al. [8], Krishnakumar and Srivastava [9], and Basner et al. [10]. Haaland [11] estimated the partial ionization cross sections for the formation of $\mathrm{Si}$ containing radicals by scaling the data of Chatham et al. [8] and the differential data of Morrison and Traeger [12] to his absolute values at $50 \mathrm{eV}$. From a theoretical standpoint, calculations for $\mathrm{SiH}_{4}$ are particularly challenging. The rigorous quantum mechanical approach for the calculations for molecules is limited to the application of simple molecules. Contrary to it, there now exist the binary encounter Bethe formalism by Ali et al. [13], the semiempirical formalismby Khare et al. [14], DM-formalism by Deutsch et al. [15], and complex potential model calculations by Joshipura et al. $[16,17]$.

This paper reports the spectrum of the single differential cross sections with the energy of secondary electron produced in the ionization of silane molecule by electron collision at fixed incident electron energies of 100 and 200 $\mathrm{eV}$, employing a semiempirical formalism based on Jain and Khare approach [18-21]. At these fixed incident electron energies, double differential cross sections as a function of angle and secondary electron energy have also been calculated. This is the only formulation that enables us to evaluate the energy and angle dependent cross sections for molecules corresponding to the formation of cations in electron-molecule collisions. To the best of our knowledge, no experimental and/or theoretical data is available for comparison to the present calculations for differential cross sections. Thus the corresponding derived integral cross 
sections in terms of the partial ionization cross sections leading to the formation of various cations $\mathrm{SiH}_{n}{ }^{+}(n=0-$ 3), $\mathrm{H}_{2}^{+}$, and $\mathrm{H}^{+}$through dissociation of $\mathrm{SiH}_{4}$ by electron collision are compared with the available experimental and theoretical data. The present results alongwith the total ionization cross sections show good agreement with the experimental and theoretical results. In addition, we have calculated the ionization rate coefficients corresponding to the produced cations using the computed ionization cross sections and Maxwell-Boltzmann distribution for the electrons as a function of electron temperature/energy. Instead of cross sections itself, ionization rate coefficients corresponding to the produced cations are more important in various plasma applications, gas discharge, and flowing afterglow studies [22, 23].

\section{Theoretical}

The present calculations are carried out using the modified semiempirical formalism developed by Pal et al. (see discussion in [18-21]). In brief, the single differential cross sections in the complete solid angle $\left(\Omega=4 \pi=\int 2 \pi \sin \theta d \theta\right)$ as a function of secondary electron energy $\varepsilon$ corresponding to the production of $i$ th type of ion in the ionization of a molecule by incident electron of energy $E$ is given by

$$
\begin{aligned}
& Q_{i}(E, W) \\
& \begin{array}{l}
=\frac{a_{0}^{2} R}{E}[ \\
\quad\left(1-\frac{\varepsilon}{\left(E-I_{i}\right)}\right) \frac{R}{W} \frac{d f_{i}(W, 0)}{d W} \ln \left[1+C_{i}\left(E-I_{i}\right)\right] \\
\left.\quad+\frac{R}{E} S_{i} \frac{\left(E-I_{i}\right)}{\left(\varepsilon_{0}^{3}+\varepsilon_{i}^{3}\right)}\left(\varepsilon-\frac{\varepsilon^{2}}{(E-\varepsilon)}+\frac{\varepsilon^{3}}{(E-\varepsilon)^{2}}\right)\right] \\
\quad \times \int 2 \pi \sin \theta d \theta,
\end{array}
\end{aligned}
$$

where $W\left(=\varepsilon+I_{i}\right)$ is defined as energy loss suffered by the incident electron. $I_{i}, a_{0}, \varepsilon_{0}, C_{i}, S_{i}$, and $R$ are the ionization threshold for the production of ith type of ion, the Bohr radius, energy parameter, collision parameter, number of ionizable electrons, and the Rydberg constant, respectively.

In the present formulation, the dipole oscillator strengths $d f_{i} / d W$ are the key parameters. The oscillator strength is directly proportional to the photoionization cross section [3]. We have used partial photoionization cross section data set in the energy range from 12 to $52 \mathrm{eV}$ provided by Brion et al. [6] using (e,e) spectroscopy. The accuracy of the determined oscillator strength scales was estimated to be better than $\pm 5 \%$. In the photon energy range $52-180 \mathrm{eV}$, we have used their measured total valence photoabsorption oscillator strength data [5], and for higher photon energy range $W>180 \mathrm{eV}$ the same were extrapolated by ThomasReiche-Kuhn (TRK) sum rule (within $\pm 10 \%$ error bars) (see, e.g., $[5,6]$ ). The total photoabsorption cross sections have been distributed into ionic fragments considering the constant ionization efficiency to be 1.0 above the dipole breakdown limit of $\sim 25 \mathrm{eV}$. However, its evaluation is possible quantum mechanically using the suitable wave functions and transition probabilities corresponding to the

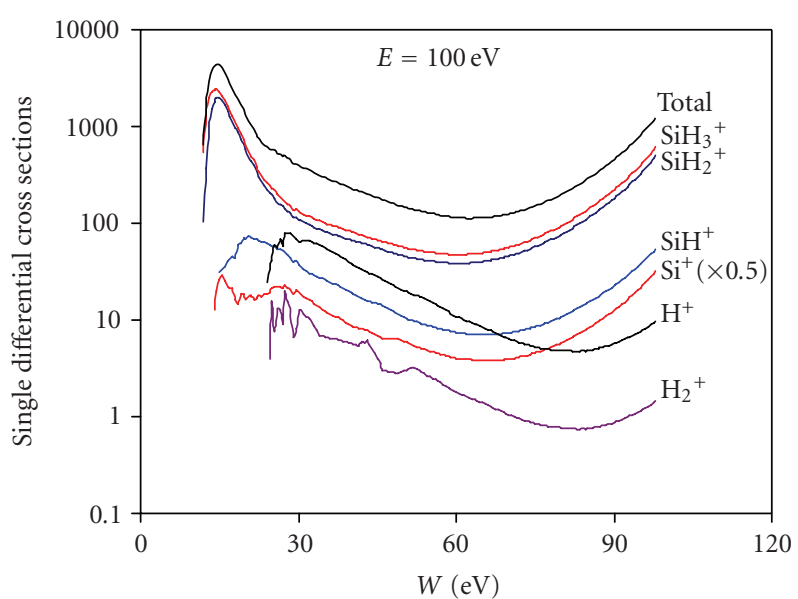

(a)

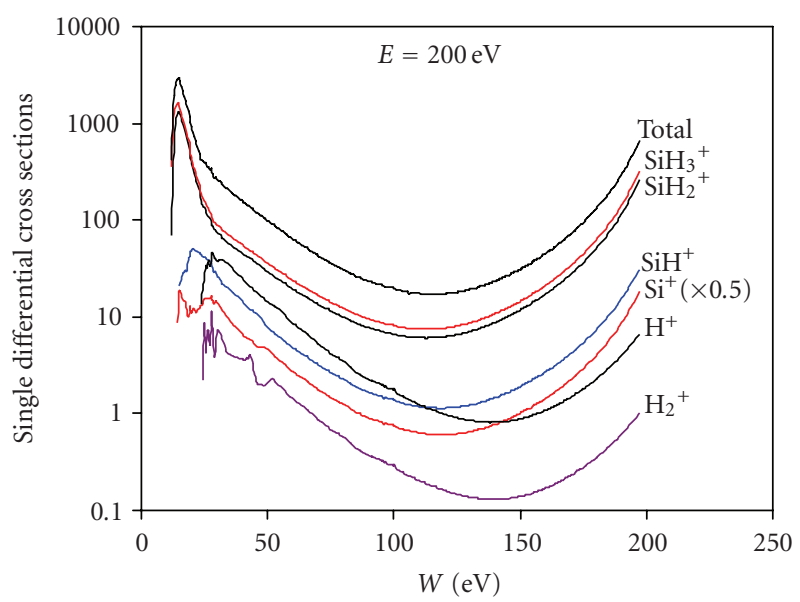

(b)

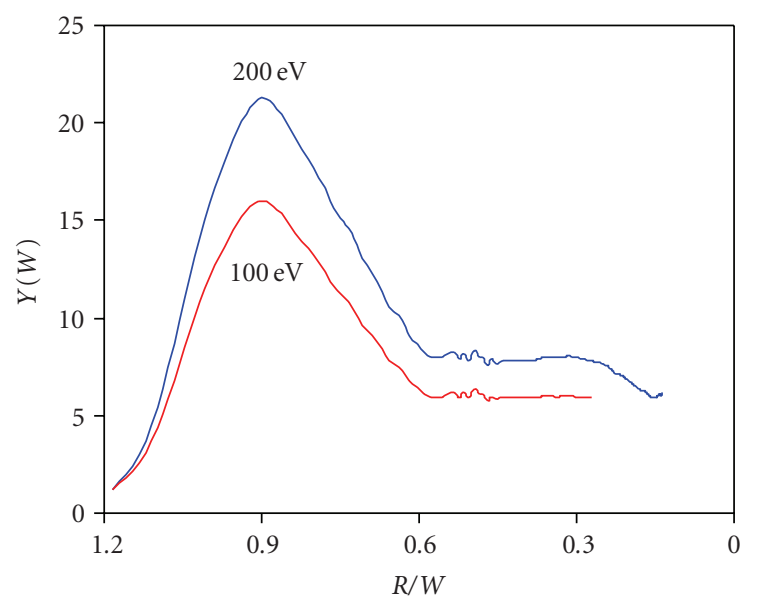

(c)

Figure 1: (a) Single differential cross sections (in the units of $\left.10^{-20} \mathrm{~cm}^{2} / \mathrm{eV}\right)$ as a function of energy loss $W\left(=I_{i}+\varepsilon\right)$, for the production of cations from electron impact ionization of $\mathrm{SiH}_{4}$ at constant electron impact energy of $100 \mathrm{eV}$. (b) Same as (a) but at $E=200 \mathrm{eV}$. (c) The solid lines show the trends of the calculated ratios of cross sections in Platzman plot $Y(W)$ in half energy range at 100 and $200 \mathrm{eV}$. 


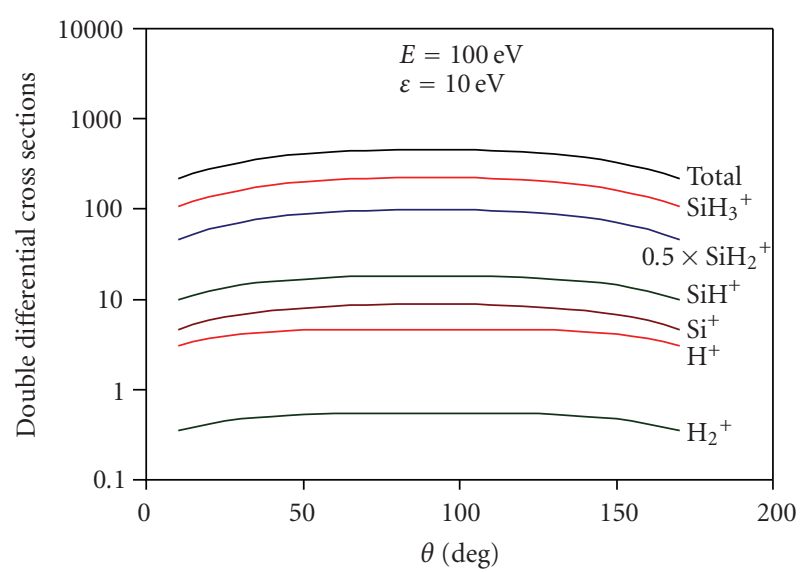

(a)

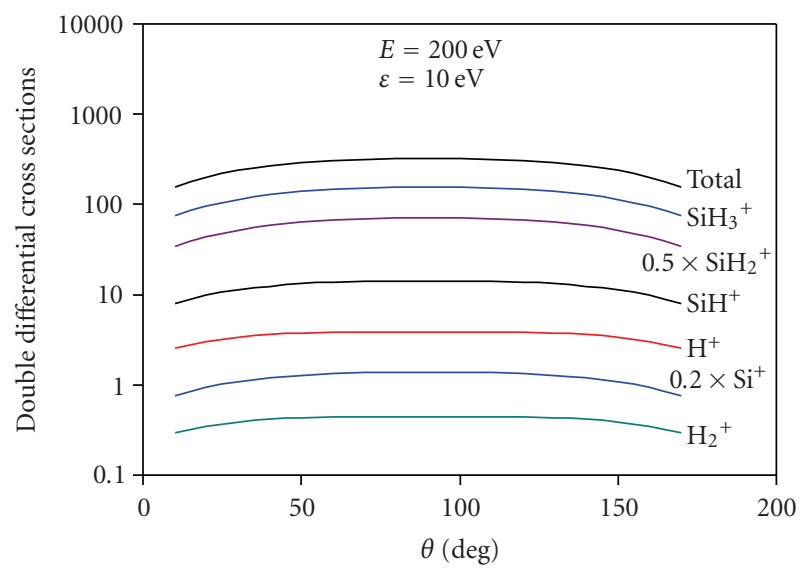

(c)

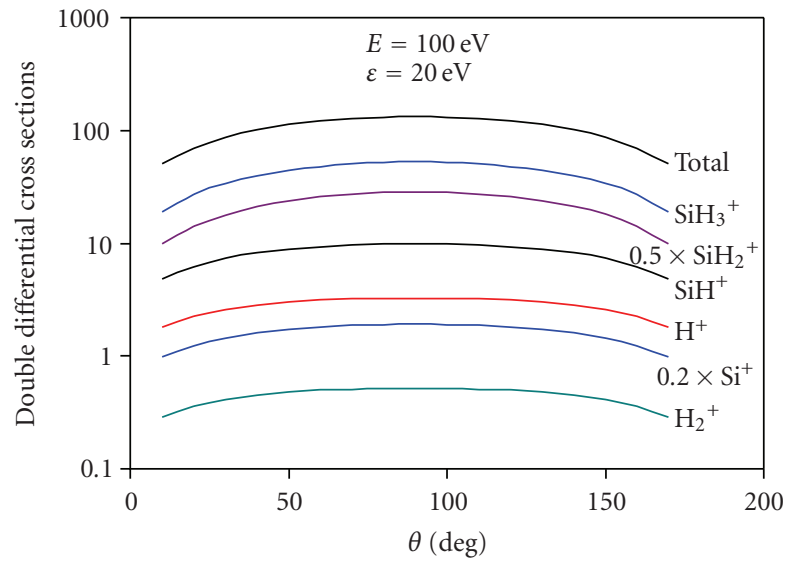

(b)

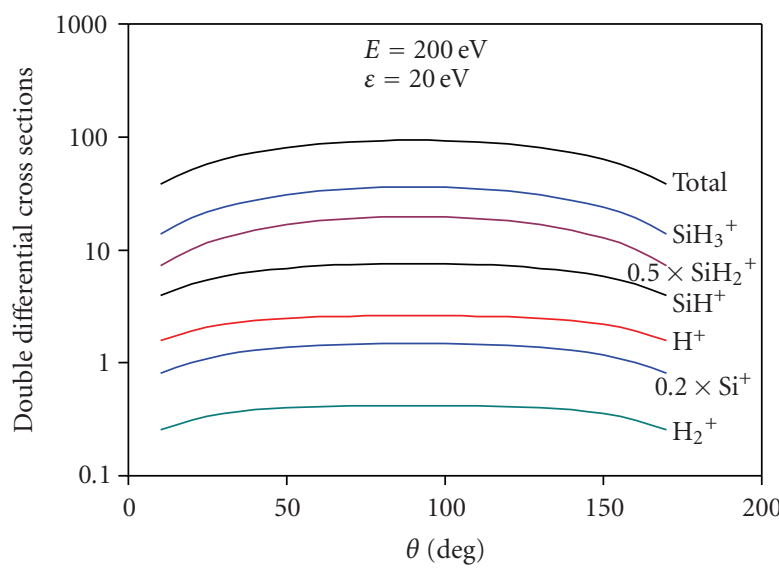

(d)

Figure 2: (a) The double differential cross sections (in the units of $10^{-20} \mathrm{~cm}^{2} / \mathrm{eV}$-sr) as a function of angle $\theta$ at $(\varepsilon=10 \mathrm{eV}$ and $E=100 \mathrm{eV}$ ) corresponding to the production of various cations from electron impact ionization of $\mathrm{SiH}_{4}$. (b) Same as (a) but at $(\varepsilon=20 \mathrm{eV}$ and $E=$ $100 \mathrm{eV})$. (c) Same as (a) but at $(\varepsilon=10 \mathrm{eV}$ and $E=200 \mathrm{eV})$. (d) Same as (a) but at $(\varepsilon=20 \mathrm{eV}$ and $E=200 \mathrm{eV})$.

production of cations. In case of dissociative ionization of polyatomic molecule $\mathrm{SiH}_{4}$, we have no reliable probabilities corresponding to different dissociative ionization processes. The collision parameter $C_{i}(=0.08621 / \mathrm{eV})$ and energy parameter $\varepsilon_{0}(=30 \mathrm{eV})$ are evaluated as for other polyatomic molecules [18-21]. The vertical onsets or the ionization potentials corresponding to the various cations are also given alongwith the photoionization measurements $[5,6]$. In the present evaluations of cross sections, the estimated uncertainty is more or less the same as for the measurement of photoionization cross sections.

The double differential cross sections as a function of energy and angle were evaluated by the differentiation of (1) with respect to the solid angle $\Omega$ as follows:

$$
Q_{i}(E, W, \theta)=\frac{d Q_{i}(E, W)}{d \Omega} .
$$

The double differential cross sections are angular dependant in all the scattering geometries, and hence the oscillator strength must be angle dependent. In this context, we have used the angular oscillator strengths that were derived in the optical limit (Bethe regime) where angular-momentumtransfer $K \rightarrow 0$ (e.g., see [19] for a detailed discussion):

$$
\frac{d f_{i}(W, 0, \theta)}{d W d \Omega}=\frac{1}{4 \pi} \frac{d f_{i}(W, 0)}{d W}\left[1+\frac{\beta}{2}\left(3 \cos ^{2} \theta-1\right)\right],
$$

where $\beta$ is an energy dependent asymmetric parameter. Its evaluation is difficult due to the lack of wave functions of molecular ions in ground and excited states. In valance shell ionization of $\mathrm{SiH}_{4}$, we have computed $\beta$ as the ratio of the Bethe spectral transitions $S_{i}(W)$ to the dipole matrix squared $M_{i}^{2}(W)[24,25]$. The oscillator strength appeared in (1) is simply a derived form of (3) in the forward scattering corresponding $K \rightarrow 0$ and $\theta \rightarrow 0$.

The partial ionization cross section is obtained by the integration of the energy dependent single differential cross sections (1) over the entire energy loss as follows:

$$
Q_{i}(E)=\int_{I_{i}}^{E} Q_{i}(E, W) d W
$$




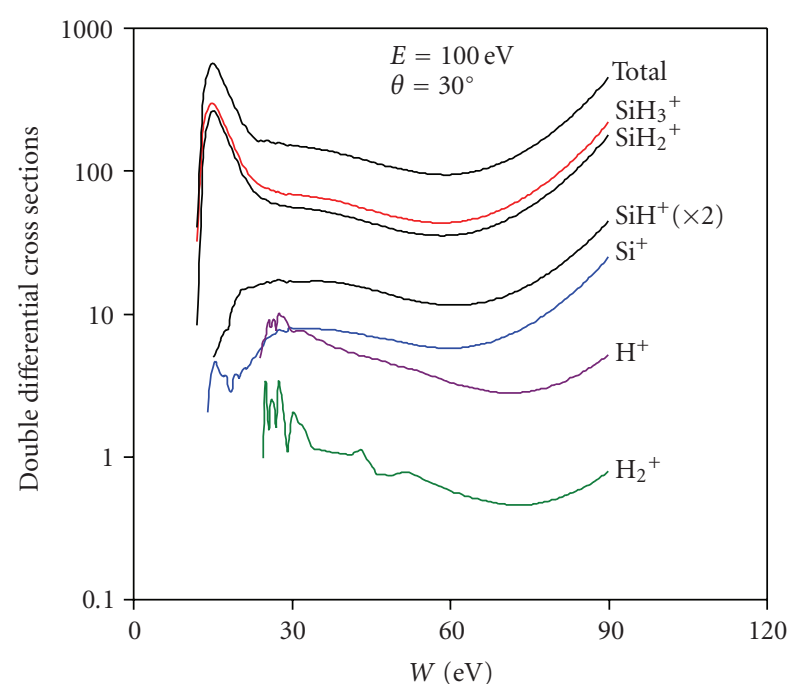

(a)

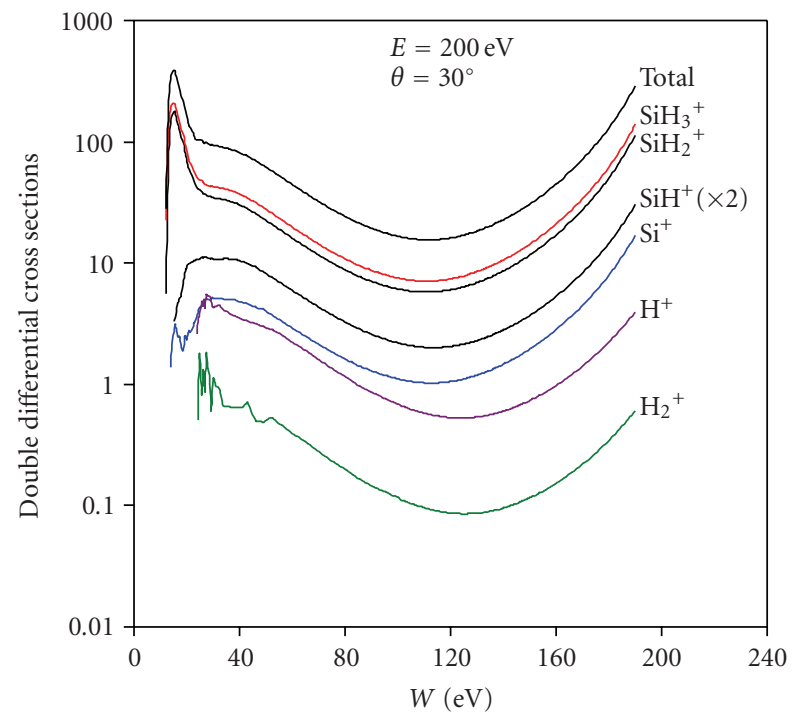

(c)

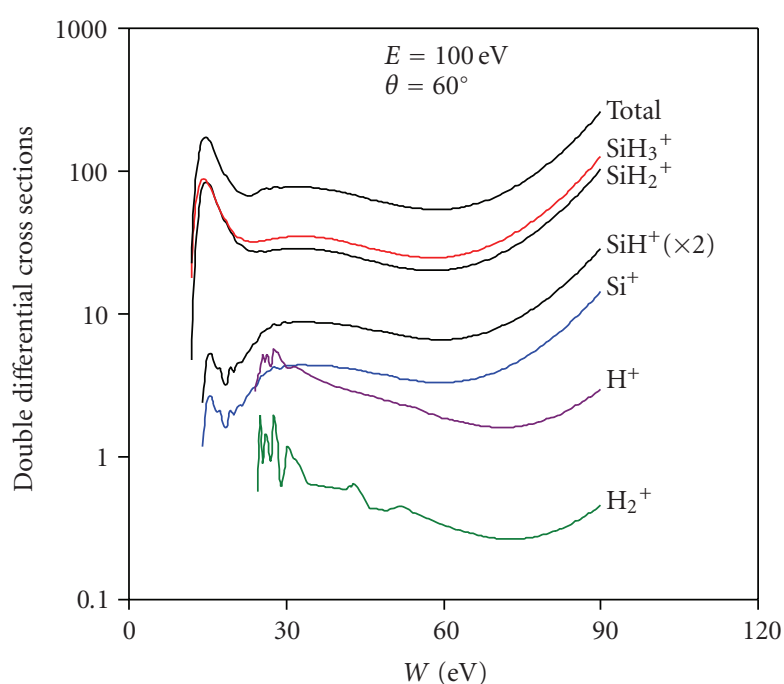

(b)

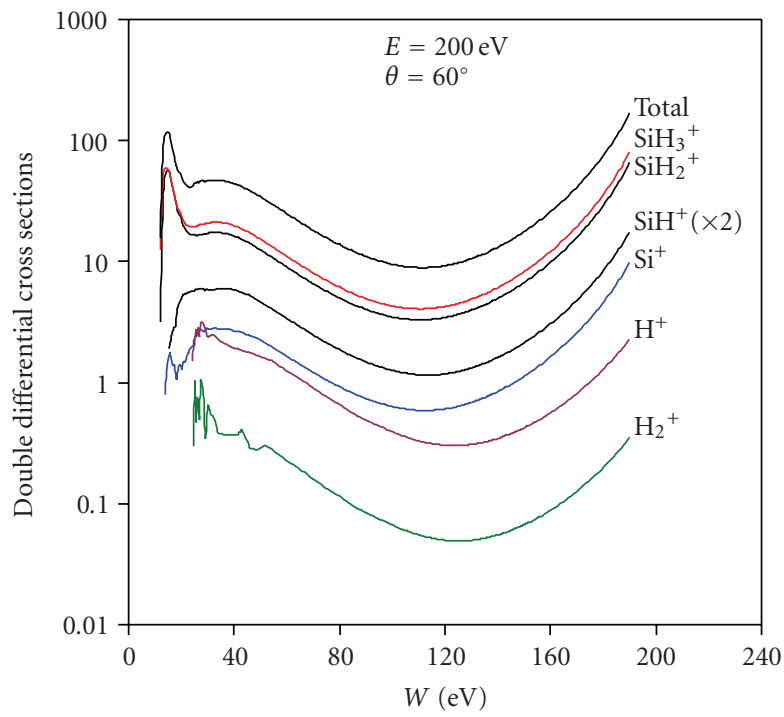

(d)

Figure 3: (a) The double differential cross sections (in the units of $10^{-20} \mathrm{~cm}^{2} / \mathrm{eV}$-sr) as a function of energy loss $W$ at $\left(\theta=30^{\circ}\right.$ and $E=100 \mathrm{eV}$ ) for the production of cations from electron impact ionization of $\mathrm{SiH}_{4}$. (b) Same as (a) but at $\left(\theta=60^{\circ}\right.$ and $\left.E=100 \mathrm{eV}\right)$. (c) Same as (a) but at $\left(\theta=30^{\circ}\right.$ and $\left.E=200 \mathrm{eV}\right)$. (d) Same as (a) but at $\left(\theta=60^{\circ}\right.$ and $\left.E=200 \mathrm{eV}\right)$.

and the counting or total ionization cross section is obtained by

$$
Q^{T}(E)=\sum_{i} Q_{i}(E)
$$

In plasma processes, the ionization rate coefficients are important quantities which are determined by using our calculated partial and total ionization cross sections and Maxwell-Boltzmann distribution of temperature/energy [26, 26] as follows:

$$
R_{i}=\int_{-\infty}^{+\infty} 4 \pi\left(\frac{1}{2 \pi m k T}\right)^{3 / 2} m e^{(-E / k T)} Q_{i}(E) E d E
$$

where $k, T$, and $m$ are the Boltzmann constant, absolute temperature, and mass of the electron, respectively.

\section{Results and Discussion}

The electronic configuration of the ground state of silane is $\mathrm{K}^{2} \mathrm{~L}^{8}\left(3 \mathrm{a}_{1}\right)^{2}\left(2 \mathrm{t}_{2}\right)^{6}{ }^{1} \mathrm{~A}_{1}$. Ionization of the outermost $2 \mathrm{t}_{2}$ electrons results in a degenerate ${ }^{2} \mathrm{~T}_{2}$ ion state, which is subject to the Jahn-Teller effect. Experimentally, $2 \mathrm{t}_{2}$ electron ionization or the parent ion formation, observed by Berkowitz et al. [27] at adiabatic ionization potential, is the best evidence for the photogeneration of a bound $\mathrm{SiH}_{4}{ }^{+}$species. The amount of molecular ions detected experimentally were approximately two orders of magnitude lower than the intensities of the dissociative ionization products $\mathrm{SiH}_{n}{ }^{+}(n$ $=0-3)$. On the other hand, due to the instability of $\mathrm{SiH}_{4}{ }^{+}$, it decomposes into other stable ions. The present calculations for cross sections are based on the experimental data for the 


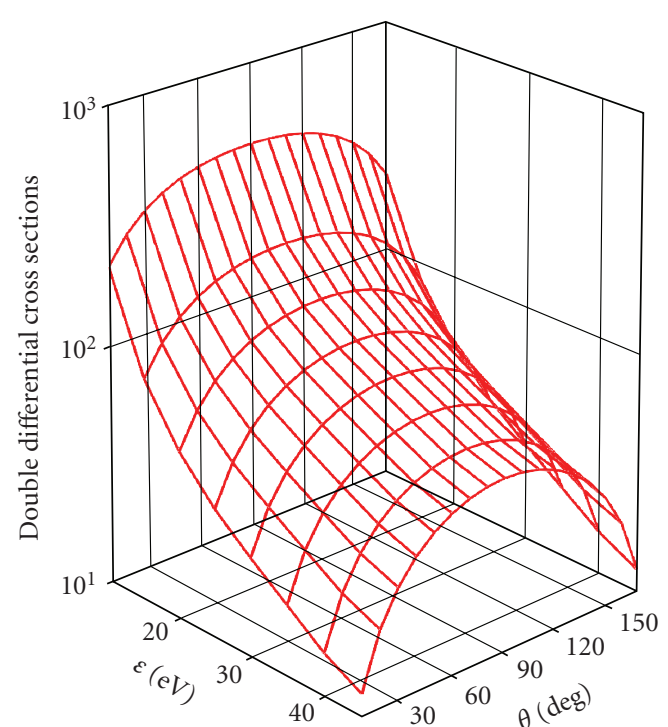

(a)

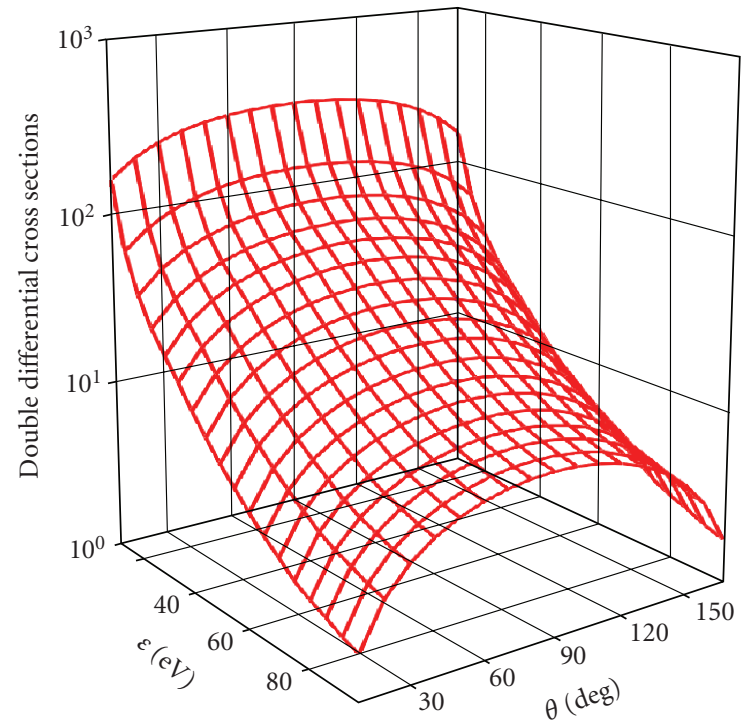

(b)

Figure 4: (a) 3D profiles of the double differential cross sections (in the units of $10^{-20} \mathrm{~cm}^{2} / \mathrm{eV}$-sr) as a function of secondary electron energy $\varepsilon$ and angle $\theta$ at $E=100 \mathrm{eV}$. (b) Same as (a) but at $E=$ $200 \mathrm{eV}$.

oscillator strengths (photoionization cross sections) $[5,6]$. The calculations for differential and integral cross sections were carried out for the produced cations $\mathrm{SiH}_{n}{ }^{+}(n=0-3)$, $\mathrm{H}_{2}{ }^{+}$, and $\mathrm{H}^{+}$through electron dissociation of $\mathrm{SiH}_{4}$.

The partial single differential cross sections as a function of secondary electron energy in terms of energy loss $W$ at fixed incident electron energies of 100 and $200 \mathrm{eV}$ are presented in Figure 1. More qualitative results are also presented in the Platzman plot of $Y(W)$. The $Y(W)$ parameter is the ratio of the calculated differential cross section and the Rutherford cross section with energy loss $W$ in the dipole energy range. Qualitatively, $Y(W)$ corresponds to the effective number of electrons participating in ionizing collisions. In the present formulation (1), the first Born-Bethe part for slow secondary electron, corresponds to the growing contribution of the dipole-allowed interaction (known as glancing collision) and resembles the photoionization cross section. The second part accounts for the electron exchange effect and corresponds to the nondipole part that defines knock-on collisions. For fast secondary electrons, it is an adaptation of the Rutherford cross sections for the free electrons.

In Figure 2, we show the behavior of double differential cross sections with angle varying from $10^{\circ}$ to $180^{\circ}$ at constant secondary electron energies of 10 and $20 \mathrm{eV}$ and fixed primary electron energies of 100 and $200 \mathrm{eV}$. The calculations as a function of energy loss $W$, at constant angles of $30^{\circ}$ and $60^{\circ}$ at the same incident electron energies, are presented in Figure 3. The 3D profiles of the total double cross sections as a function of secondary electron energy (in the range of $5 \mathrm{eV}$ to $W / 2)$ and angle $\left(10^{\circ}\right.$ to $\left.180^{\circ}\right)$ at 100 and $200 \mathrm{eV}$ are also shown in Figure 4. To the best of our knowledge, no experimental data is available to compare the present results for differential cross sections. However, the qualitative behavior of the cross section is the same as for other molecules investigated [18-21]. The energy dependent cross sections are symmetric at $W / 2$ where the energies of primary and the secondary electrons are almost equal. The figures clearly show the weight contribution of the molecular and atomic cations. The cross sections for molecular ions are much larger than the atomic ions. In dipole-induced breakdown scheme for the photoionization of silane molecule, the major ions $\mathrm{SiH}_{3}{ }^{+}$and $\mathrm{SiH}_{2}{ }^{+}$are produced from $2 \mathrm{t}_{2}{ }^{-1}$ state, and the $\mathrm{H}^{+}$and $\mathrm{H}_{2}{ }^{+}$ions are produced from $3 \mathrm{a}_{1}{ }^{-1}$ state, while the production of the $\mathrm{SiH}^{+}$ and $\mathrm{Si}^{+}$ions comes from the contribution of the both states. In the threshold energy range, the atomic photoionization cross sections include the contribution of the structures and many body states produced near onsets $[5,6]$ which are reflected in the present calculations for energy dependent differential cross sections.

Because of the lack of experimental data for differential cross sections, the corresponding derived partial cross sections and their sum (the total ionization cross sections), from ionization threshold to $1000 \mathrm{eV}$, become important. The numerical values of our calculated partial and the total ionization cross sections are presented in Table 1. In Figure 5, we have presented the comparison of our partial ionization cross sections with the established experimental data sets of Chatham et al. [8], Krishnakumar and Srivastava [9], and Basner et al. [10]. It is noted that for the $\mathrm{SiH}_{n}{ }^{+}$ ( $n=0-3)$ ions, our results are in good agreement with the experimental data $[8,10]$ within their composite error bars (The measurements of Chatham et al., Krishnakumar and Srivastava, and Basner et al. account the experimental uncertainties $30 \%-40 \%, 15 \%$, and $10 \%-20 \%$, resp.). On the other hand the experimental data of Haaland [11] which is a scaled value of Chatham et al. [8] and the Morrison and Traeger [12] are lower by a factor of two to three than the present calculations as well as the other experimental 


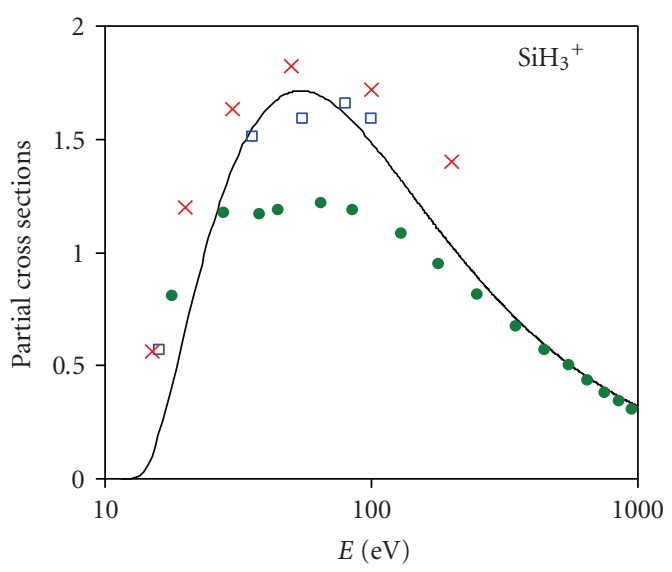

(a)

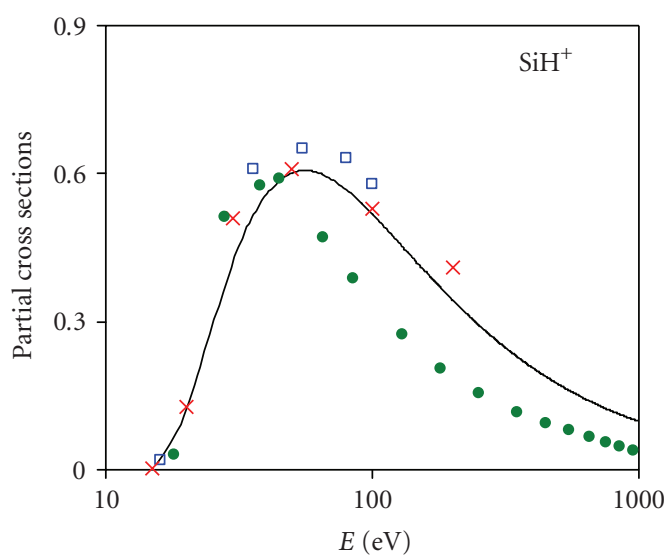

(c)

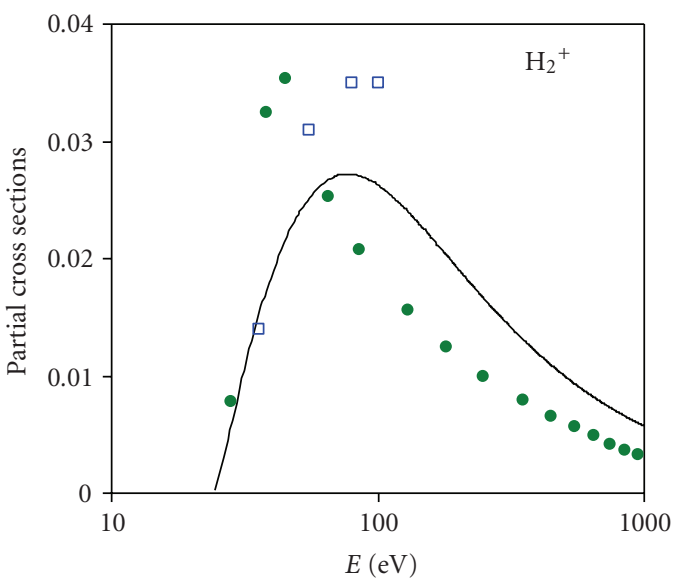

(e)

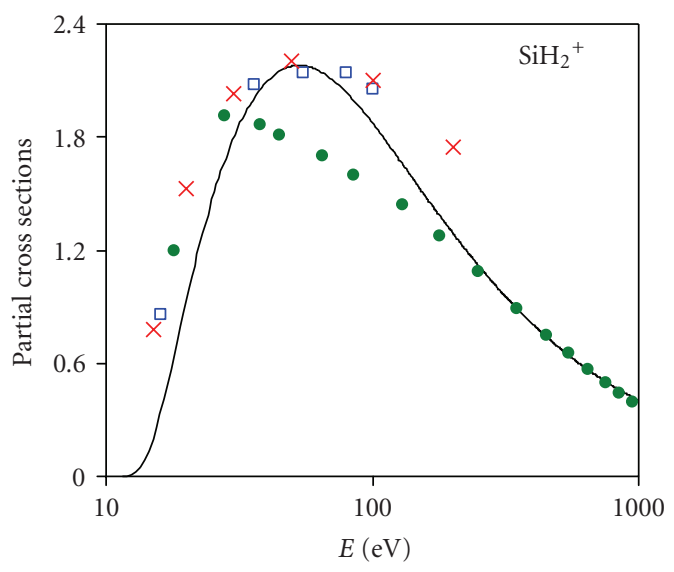

(b)

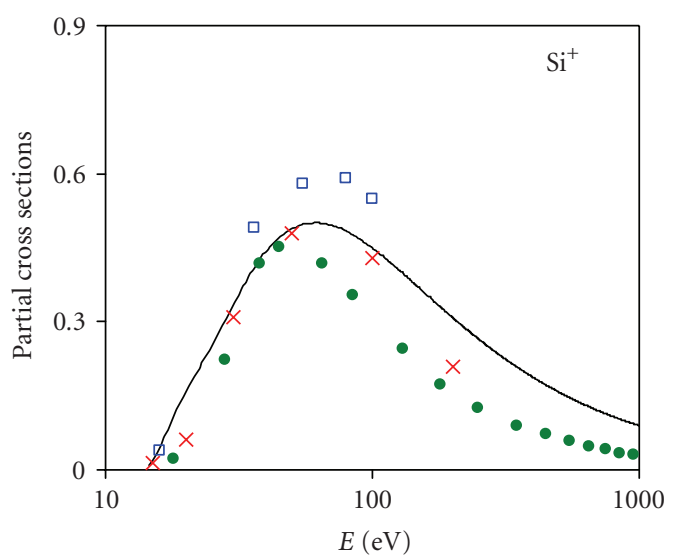

(d)

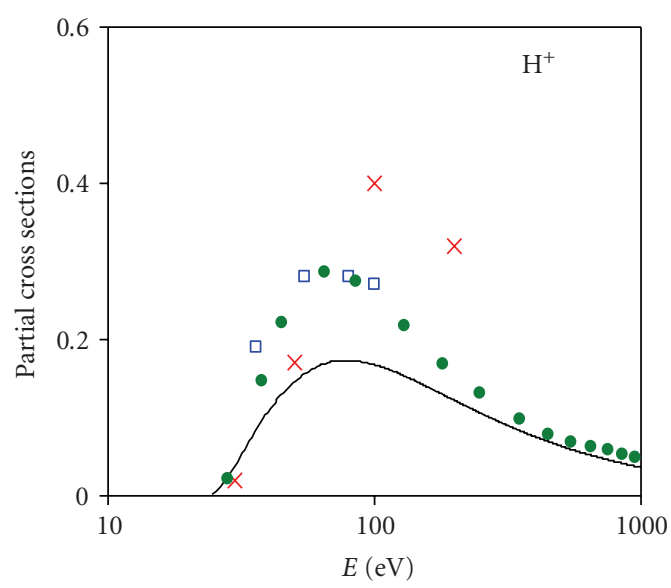

(f)

FIgURE 5: Partial ionization cross sections (in the units of $10^{-16} \mathrm{~cm}^{2}$ ) for electron impact ionization of $\mathrm{SiH}_{4}$ (designated with solid lines) in comparison with the experimental data designated by $\times$ - Chatham et al. [8], ๑-Krishnakumar and Srivastava [9], and $\square-$ Basner et al. $[10]$.

data sets [8-10]. Hence for the sake of reasonable shape and size of the figure, the data of Haaland is not shown in the figure. For the $\mathrm{H}_{2}{ }^{+}$and $\mathrm{H}^{+}$ions, a considerable disagreement with the experimental data has been noticed. However, our calculations for $\mathrm{H}_{2}{ }^{+}$agree well with recent data of Basner et al., while the data set of Chatham (not shown) is much higher than the present calculations and the data of Basner et al. The data of Chatham et al. is about 3 and 4 times higher than Basner et al. and our calculations for $\mathrm{H}^{+}$, respectively. No identification of $\mathrm{H}^{+}$and $\mathrm{H}_{2}{ }^{+}$ions was made in earlier investigations $[7,11,12]$. In case of all dissociative fragment ions, the experimental data of Krishnakumar and 


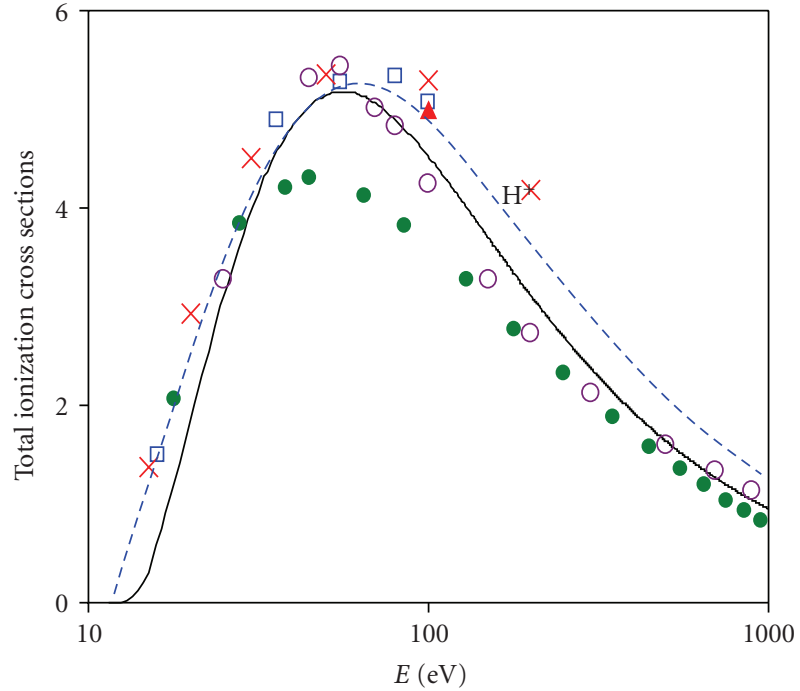

Figure 6: Presently calculated total ionization cross sections (in the units of $10^{-16} \mathrm{~cm}^{2}$ ) for electron impact ionization of $\mathrm{SiH}_{4}$ (designated by solid line) in comparison with the various experimental data sets designated by $\Delta-$ Perrin et al. [7], $\times-$ Chatham et al. [8], ๑-Krishnakumar and Srivastava [9], and $\square-$ Basner et al. [10] and theoretical data sets designated by - - BEB calculations $[13,28]$ and $\bigcirc-$ Joshipura et al. $[16,17]$.

Srivastava [9] show disagreement with our calculations as well as other experimental data $[8,10]$ in the energy range from 40 to $500 \mathrm{eV}$. Nevertheless, considering that this is a comparison with the absolute data where error bars of these sets of data are easily in the $10 \%$ to $40 \%$ regime (in particular taking into account that the calculations are depending on the accuracy of the experimental input parameters), the agreement is acceptable.

Figure 6 shows good agreement of the partial cross sections when added up to a total cross section with the experimental data sets [8-10] along with the experimental data of Perrin et al. [7] which is available only at $100 \mathrm{eV}$ and theoretical cross section data sets $[13,16,17]$ in the complete energy range covered in the calculations. Recently, Malcolm and Yeager [28] have reviewed the BEB model [13] employing the more accurate ionization potential evaluation from Hartree-Fock theorem using cc-pVDZ and cc-pVTZ basis sets with multiconfigurational self-consistent field. This approach is a viable method for calculating electron impact ionization cross sections for systems where Koopman's theorem is known to be unreliable, or no experimental data is available. However, in case of this open channel molecule $\mathrm{SiH}_{4}$, these calculations for total ionization cross sections do not have a significant effect on the data derived from BEB (see [28] for detailed discussion). The data of Krishnakumar and Srivastava [9] for total cross sections show similar trends as for dissociative ionization cross sections. The total ionization cross sections reported by Haaland [11] are much smaller than all the measured data sets and the calculations. Hence for the sake of brevity, we have not shown the same data [11] in the comparison.
TABLE 1: Table for the partial ionization cross sections for $\mathrm{SiH}_{4}$ by electron impact.

\begin{tabular}{lccccccc}
\hline \multirow{2}{*}{$E(\mathrm{eV})$} & \multicolumn{7}{c}{$\mathrm{Q}_{i}(E)\left(10^{-16} \mathrm{~cm}^{2}\right)$} \\
& $\mathrm{SiH}_{3}{ }^{+}$ & $\mathrm{SiH}_{2}{ }^{+}$ & $\mathrm{SiH}^{+}$ & $\mathrm{Si}^{+}$ & $\mathrm{H}_{2}{ }^{+}$ & $\mathrm{H}^{+}$ & Total \\
\hline 20 & 0.71 & 1.00 & 0.14 & 0.17 & & & 2.02 \\
30 & 1.39 & 1.81 & 0.43 & 0.34 & 0.01 & 0.04 & 4.02 \\
40 & 1.63 & 2.10 & 0.56 & 0.45 & 0.02 & 0.11 & 4.87 \\
50 & 1.71 & 2.18 & 0.60 & 0.49 & 0.02 & 0.15 & 5.15 \\
60 & 1.70 & 2.16 & 0.60 & 0.50 & 0.03 & 0.16 & 5.16 \\
70 & 1.66 & 2.11 & 0.59 & 0.50 & 0.03 & 0.17 & 5.05 \\
80 & 1.61 & 2.03 & 0.57 & 0.48 & 0.03 & 0.17 & 4.89 \\
90 & 1.54 & 1.95 & 0.54 & 0.47 & 0.03 & 0.17 & 4.70 \\
100 & 1.48 & 1.87 & 0.52 & 0.45 & 0.03 & 0.17 & 4.51 \\
125 & 1.34 & 1.69 & 0.46 & 0.41 & 0.02 & 0.16 & 4.07 \\
150 & 1.22 & 1.53 & 0.41 & 0.37 & 0.02 & 0.14 & 3.69 \\
200 & 1.03 & 1.29 & 0.34 & 0.31 & 0.02 & 0.12 & 3.11 \\
250 & 0.89 & 1.12 & 0.29 & 0.26 & 0.02 & 0.11 & 2.69 \\
300 & 0.79 & 0.99 & 0.26 & 0.23 & 0.01 & 0.09 & 2.37 \\
400 & 0.64 & 0.81 & 0.21 & 0.19 & 0.01 & 0.08 & 1.93 \\
500 & 0.55 & 0.68 & 0.17 & 0.16 & 0.01 & 0.06 & 1.63 \\
600 & 0.48 & 0.60 & 0.15 & 0.14 & 0.01 & 0.06 & 1.42 \\
700 & 0.42 & 0.53 & 0.13 & 0.12 & 0.01 & 0.05 & 1.26 \\
800 & 0.38 & 0.48 & 0.12 & 0.11 & 0.01 & 0.04 & 1.14 \\
900 & 0.35 & 0.44 & 0.11 & 0.10 & 0.01 & 0.04 & 1.03 \\
\hline & & & & & & &
\end{tabular}

The present calculations for partial and total ionization cross sections satisfy the necessary consistency checks to access their consistency and reliability. The consistency checks are derived from the fact that the total electron impact ionization cross section (i) is equal to the charged-weighted sum of the partial ionization cross sections and (ii) may be obtained by integration of the differential cross sections over secondary electron energies and angles. The former condition is used in the summation method for calibration purposes and the later fact in the use of Platzman plots. Both relationships allow one to check the reliability of the absolute magnitude and the energy dependence of ionization cross sections under consideration. In the low-energy limit close to the onset of ionization, the shapes of the partial and total electron impact ionization cross section curves are governed by a threshold law, which is usually expressed in the form of $Q(E) \sim\left(E-I_{i}\right)^{Z}$, where $Z$ is the charge state of the ion. The precise shape of the cross section in this region is especially important in determination (by extrapolation) of respective ionization thresholds, to compare with those derived by other means [29-31].

In relation to the applications, in particularly to plasma processes, ionization rate coefficients are rather more desirable than ionization cross sections. We have evaluated a set of ionization rate coefficients as a function of electron temperature in the units of energy for the individual cations produced in electron collision with the $\mathrm{SiH}_{4}$ molecule. The calculations are made using the calculated ionization cross sections and Maxwell-Boltzmann energy distribution, and the results are presented in Figure 7 along with Table 2. 


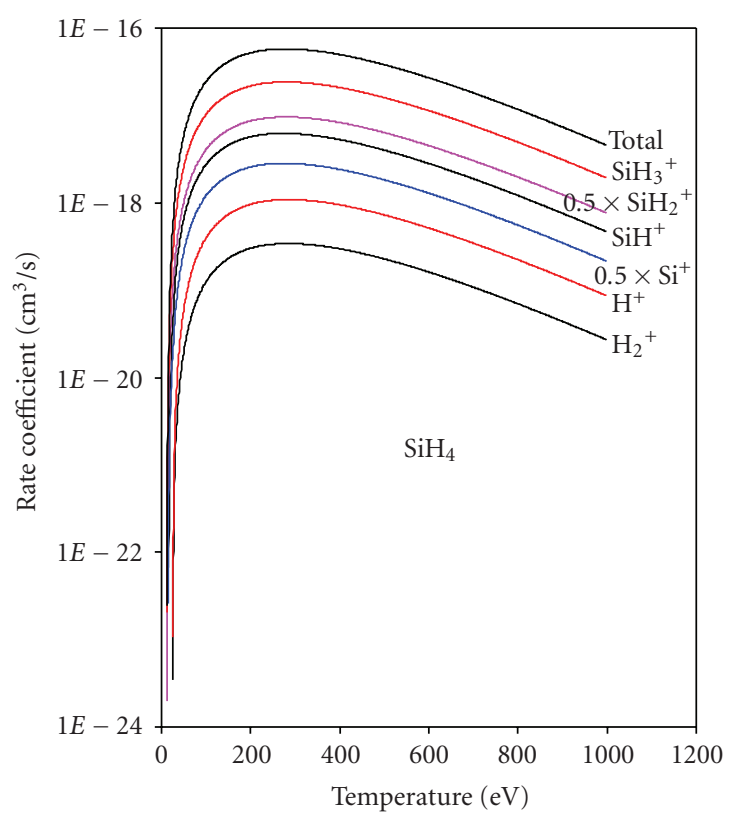

FIGURE 7: Ionization rate coefficients as a function of the temperature for $\mathrm{SiH}_{4}$.

TABLE 2: Table for the ionization rate coefficients (in the units of $10^{-20} \mathrm{~cm}^{3} / \mathrm{s}$ ) corresponding to the formation of cations in electron dissociative ionization of $\mathrm{SiH}_{4}$.

\begin{tabular}{lccccccc}
\hline$E(\mathrm{eV})$ & $\mathrm{SiH}_{3}^{+}$ & $\mathrm{SiH}_{2}{ }^{+}$ & $\mathrm{SiH}^{+}$ & $\mathrm{Si}^{+}$ & $\mathrm{H}_{2}{ }^{+}$ & $\mathrm{H}^{+}$ & Total \\
\hline 20 & 6.22 & 8.70 & 0.81 & 1.15 & & & 16.87 \\
30 & 43.42 & 56.69 & 11.36 & 9.48 & 0.11 & 0.50 & 121.56 \\
40 & 111.66 & 143.36 & 34.35 & 28.42 & 0.77 & 4.45 & 323.01 \\
50 & 204.56 & 260.65 & 66.52 & 55.54 & 2.00 & 12.21 & 601.47 \\
55 & 257.82 & 327.77 & 84.98 & 71.46 & 2.79 & 17.27 & 762.08 \\
60 & 314.43 & 399.05 & 104.55 & 88.53 & 3.67 & 22.97 & 933.21 \\
70 & 434.79 & 550.47 & 145.91 & 125.09 & 5.68 & 35.81 & 1297.75 \\
80 & 560.64 & 708.68 & 188.81 & 163.44 & 7.88 & 49.92 & 1679.38 \\
90 & 688.18 & 868.92 & 231.94 & 202.30 & 10.19 & 64.66 & 2066.18 \\
100 & 814.63 & 1027.73 & 274.36 & 240.76 & 12.52 & 79.58 & 2449.58 \\
125 & 1112.68 & 1401.83 & 373.04 & 330.92 & 18.15 & 115.55 & 3352.17 \\
150 & 1369.77 & 1724.34 & 456.55 & 407.86 & 23.10 & 147.20 & 4128.82 \\
200 & 1732.03 & 2178.41 & 570.58 & 514.06 & 30.22 & 192.61 & 5217.90 \\
250 & 1899.27 & 2387.60 & 619.23 & 560.61 & 33.63 & 214.40 & 5714.74 \\
300 & 1911.95 & 2402.83 & 617.83 & 561.09 & 34.09 & 217.37 & 5745.16 \\
400 & 1659.73 & 2085.17 & 528.62 & 481.86 & 29.72 & 189.53 & 4974.64 \\
500 & 1270.81 & 1596.30 & 400.20 & 365.58 & 22.74 & 145.03 & 3800.66 \\
600 & 900.73 & 1131.32 & 281.06 & 257.09 & 16.08 & 102.55 & 2688.84 \\
700 & 605.90 & 760.96 & 187.62 & 171.78 & 10.79 & 68.77 & 1805.81 \\
800 & 392.47 & 492.89 & 120.73 & 110.62 & 6.96 & 44.41 & 1168.08 \\
900 & 247.07 & 310.28 & 75.57 & 69.27 & 4.37 & 27.87 & 734.43 \\
\hline & & & & & & &
\end{tabular}

\section{Conclusion}

The calculations for differential cross sections as a function of secondary electron energy and angle at fixed impinging electron energy, corresponding to the formation of various cations in electron impact dissociative ionization of the $\mathrm{SiH}_{4}$ molecule, have been carried out by employing a semiempirical formalism based on the Jain-Khare approach. The calculations were made for the production of various cations produced via dissociative electron ionization of $\mathrm{SiH}_{4}$. In absence of any data for differential cross sections, the corresponding derived partial ionization cross sections revealed a good agreement with available experimental data sets. However in case of minor $\mathrm{H}^{+}$and $\mathrm{H}_{2}{ }^{+}$ions, some discrepancy was noticed. The ionization rate coefficients, a key parameter in plasma modeling, have been evaluated using a Maxwell energy distribution. The present evaluations for electron ionization cross sections and rate coefficients provide a contribution to the knowledge of various plasma processes.

\section{Acknowledgments}

NK is thankful to University Grants Commission, New Delhi for awarding project associateship with Grant no. F.30-10(2004)(SR). Anshu thanks to DAE/BRNS for junior research fellowship award through Grant no. 2007/37/ 13/BRNS.

\section{References}

[1] W. L. Morgan, "A critical evaluation of low-energy electron impact cross sections for plasma processing modeling. II: $\mathrm{Cl}_{4}$, $\mathrm{SiH}_{4}$, and $\mathrm{CH}_{4}$," Plasma Chemistry and Plasma Processing, vol. 12, no. 4, pp. 477-493, 1992.

[2] P. Kae-Nune, J. Perrin, J. Guillon, and J. Jolly, "Mass spectrometry detection of radicals in $\mathrm{SiH}_{4}-\mathrm{CH}_{4}-\mathrm{H}_{2}$ glow discharge plasmas," Plasma Sources Science and Technology, vol. 4, no. 2, pp. 250-259, 1995.

[3] J. W. Gallagher, C. E. Brion, J. A. R. Samson, and P. W. Langhoff, "Absolute cross sections for molecular photoabsorption, partial photoionization, and ionic photofragmentation processes," Journal of Physical and Chemical Reference Data, vol. 17, no. 1, pp. 9-153, 1988.

[4] R. D. Johnson III, B. P. Tsai, and J. W. Hudgens, "Multiphoton ionization of $\mathrm{SiH}_{3}$ and $\mathrm{SiD}_{3}$ radicals: electronic spectra, vibrational analyses of the ground and Rydberg states, and ionization potentials," The Journal of Chemical Physics, vol. 91, no. 6, pp. 3340-3359, 1989.

[5] G. Cooper, T. Ibuki, and C. E. Brion, "Absolute oscillator strengths for photoabsorption, photoionization and ionic photofragmentation of silane. II. The $\mathrm{Si} 2 \mathrm{p}$ and $2 \mathrm{~s}$ inner shells," Chemical Physics, vol. 140, no. 1, pp. 147-155, 1990.

[6] G. Cooper, T. Ibuki, and C. E. Brion, "Absolute oscillator strengths for photoabsorption, photoionization and ionic photofragmentation of silane. I. The valence shell," Chemical Physics, vol. 140, no. 1, pp. 133-145, 1990.

[7] J. Perrin, J. P. M. Schmitt, G. de Rosny, B. Drevillon, J. Huc, and A. Lloret, "Dissociation cross sections of silane and disilane by electron impact," Chemical Physics, vol. 73, no. 3, pp. 383-394, 1982.

[8] H. Chatham, D. Hils, R. Robertson, and A. Gallagher, "Total and partial electron collisional ionization cross sections for $\mathrm{CH}_{4}, \mathrm{C}_{2} \mathrm{H}_{6}, \mathrm{SiH}_{4}$, and $\mathrm{Si}_{2} \mathrm{H}_{6}$," The Journal of Chemical Physics, vol. 81 , no. 4, pp. 1770-1777, 1984. 
[9] E. Krishnakumar and S. K. Srivastava, "Ionization cross sections of silane and disilane by electron impact," Contributions to Plasma Physics, vol. 35, no. 4-5, pp. 395-404, 1995.

[10] R. Basner, M. Schmidt, V. Tarnovsky, K. Becker, and H. Deutsch, "Dissociative ionization of silane by electron impact," International Journal of Mass Spectrometry and Ion Processes, vol. 171, no. 1-3, pp. 83-93, 1998.

[11] P. Haaland, "Dissociative ionization of silane," Chemical Physics Letters, vol. 170, no. 2-3, pp. 146-152, 1990.

[12] J. D. Morrison and J. C. Traeger, "Ionization and dissociation by electron impact III. $\mathrm{CH}_{4}$ and $\mathrm{Sih}_{4}$," International Journal of Mass Spectrometry and Ion Physics, vol. 11, no. 3, pp. 289-300, 1973.

[13] M. A. Ali, Y.-K. Kim, W. Hwang, N. M. Weinberger, and M. E. Rudd, "Electron-impact total ionization cross sections of silicon and germanium hydrides," The Journal of Chemical Physics, vol. 106, no. 23, pp. 9602-9608, 1997.

[14] S. P. Khare, S. Prakash, and W. J. Meath, "Dissociative ionization of $\mathrm{NH}_{3}$ and $\mathrm{H}_{2} \mathrm{O}$ molecules by electron impact," International Journal of Mass Spectrometry and Ion Processes, vol. 88, no. 2-3, pp. 299-308, 1989.

[15] H. Deutsch, K. Becker, S. Matt, and T. D. Märk, “Theoretical determination of absolute electron-impact ionization cross sections of molecules," International Journal of Mass Spectrometry, vol. 197, no. 1-3, pp. 37-69, 2000.

[16] K. N. Joshipura, B. G. Vaishnav, and S. Gangopadhyay, "Electron impact ionization cross-sections of plasma relevant and astrophysical silicon compounds: $\mathrm{SiH}_{4}, \mathrm{Si}_{2} \mathrm{H}_{6}, \mathrm{Si}\left(\mathrm{CH}_{3}\right)_{4}, \mathrm{SiO}$, $\mathrm{SiO}_{2}, \mathrm{SiN}$ and SiS," International Journal of Mass Spectrometry, vol. 261, no. 2-3, pp. 146-151, 2007.

[17] M. Vinodkumar, C. Limbachiya, K. Korot, and K. N. Joshipura, "Theoretical electron impact elastic, ionization and total cross sections for silicon hydrides, $\mathrm{SiH}_{\mathrm{x}}(\mathrm{x}=1,2,3,4)$ and disilane, $\mathrm{Si}_{2} \mathrm{H}_{6}$ from threshold to $5 \mathrm{keV}$," The European Physical Journal D, vol. 48, no. 3, pp. 333-342, 2008.

[18] S. Pal, "Determination of single differential and partial crosssections for the production of cations in electron-methanol collision," Chemical Physics, vol. 302, no. 1-3, pp. 119-124, 2004.

[19] S. Pal, J. Kumar, and T. D. Märk, "Differential, partial and total electron impact ionization cross sections for $\mathrm{SF}_{6}$," The Journal of Chemical Physics, vol. 120, no. 10, pp. 4658-4663, 2004.

[20] P. Bhatt and S. Pal, "Determination of cross sections and rate coefficients for the electron impact dissociation of $\mathrm{NO}_{2}$," Chemical Physics, vol. 327, no. 2-3, pp. 452-456, 2006.

[21] S. Pal, "Differential and partial ionization cross sections for electron impact ionization of plasma processing molecules: $\mathrm{CF}_{4}$ and $\mathrm{PF}_{5}$," Physica Scripta, vol. 77, no. 5, Article ID 055304, 7 pages, 2008.

[22] M. Capitelli, R. Celiberto, and M. Cocciatore, "Needs for cross sections in plasma chemistry," Advances in Atomic, Molecular, and Optical Physics, vol. 33, pp. 321-372, 1994.

[23] T. Fujimoto, "Semi-empirical cross sections and rate coefficients for excitation and ionization by electron collision and photoionization of Helium," Institute of Plasma Physics Report, IIPJ-AM-8, Nagoya University, Nagoya, Japan, 1978.

[24] S. Pal and S. Prakash, "Partial differential cross sections for the ionization of the $\mathrm{SO}_{2}$ molecule by electron impact," Rapid Communications in Mass Spectrometry, vol. 12, no. 6, pp. 297301, 1998.

[25] M. Inokuti, "Inelastic collisions of fast charged particles with atoms and molecules - the bethe theory revisited," Reviews of Modern Physics, vol. 43, no. 3, pp. 297-347, 1971.
[26] H. Deutsch, K. Becker, G. Senn, S. Matt, and T. D. Märk, "Calculation of cross sections and rate coefficients for the electron impact multiple ionization of beryllium, boron, carbon, and oxygen atoms," International Journal of Mass Spectrometry, vol. 192, no. 1-3, pp. 1-8, 1999.

[27] J. Berkowitz, J. P. Greene, H. Cho, and B. Ruščić, "Photoionization mass spectrometric studies of $\mathrm{SiH}_{n}(n=1-4)$," The Journal of Chemical Physics, vol. 86, no. 3, pp. 1235-1248, 1987.

[28] N. O. J. Malcolm and D. L. Yeager, "Purely theoretical electronimpact ionization cross-sections of silicon hydrides and silicon fluorides obtained from explicitly correlated methods," The Journal of Chemical Physics, vol. 113, no. 1, pp. 8-17, 2000.

[29] T. D. Märk, "Ionization of molecules by electron impact," in Electron-Molecule Interactions and Their Applications, L. G. Christophorou, Ed., vol. 1, pp. 251-334, Academic Press, Orlando, Fla, USA, 1984.

[30] "Secondary electron spectra by charged particles interactions," ICRU Report 55, International Commission on Radiation Units and Measurements, Bethesda, Md, USA, 1996.

[31] P. G. Burke, "Theory of electron scattering by atoms, ions and molecules," in Proceedings of the 2nd International Conference on Atomic and Molecular Data and Their Applications (ICAMDATA '00), K. A. Berrington and K. L. Bell, Eds., pp. 155-177, AIOP, Oxford, UK, March 2000. 


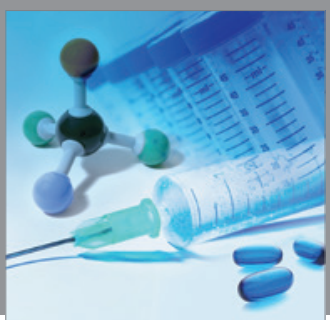

International Journal of

Medicinal Chemistry

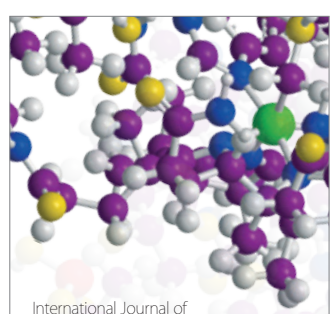

Carbohydrate Chemistry

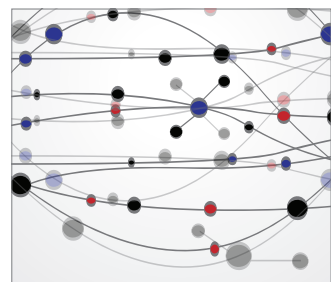

The Scientific World Journal
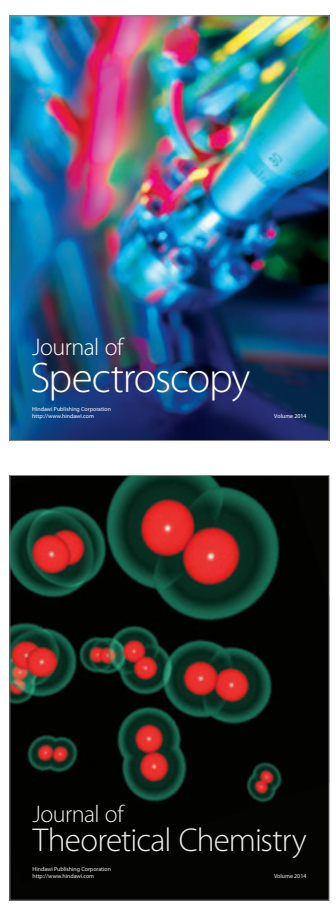
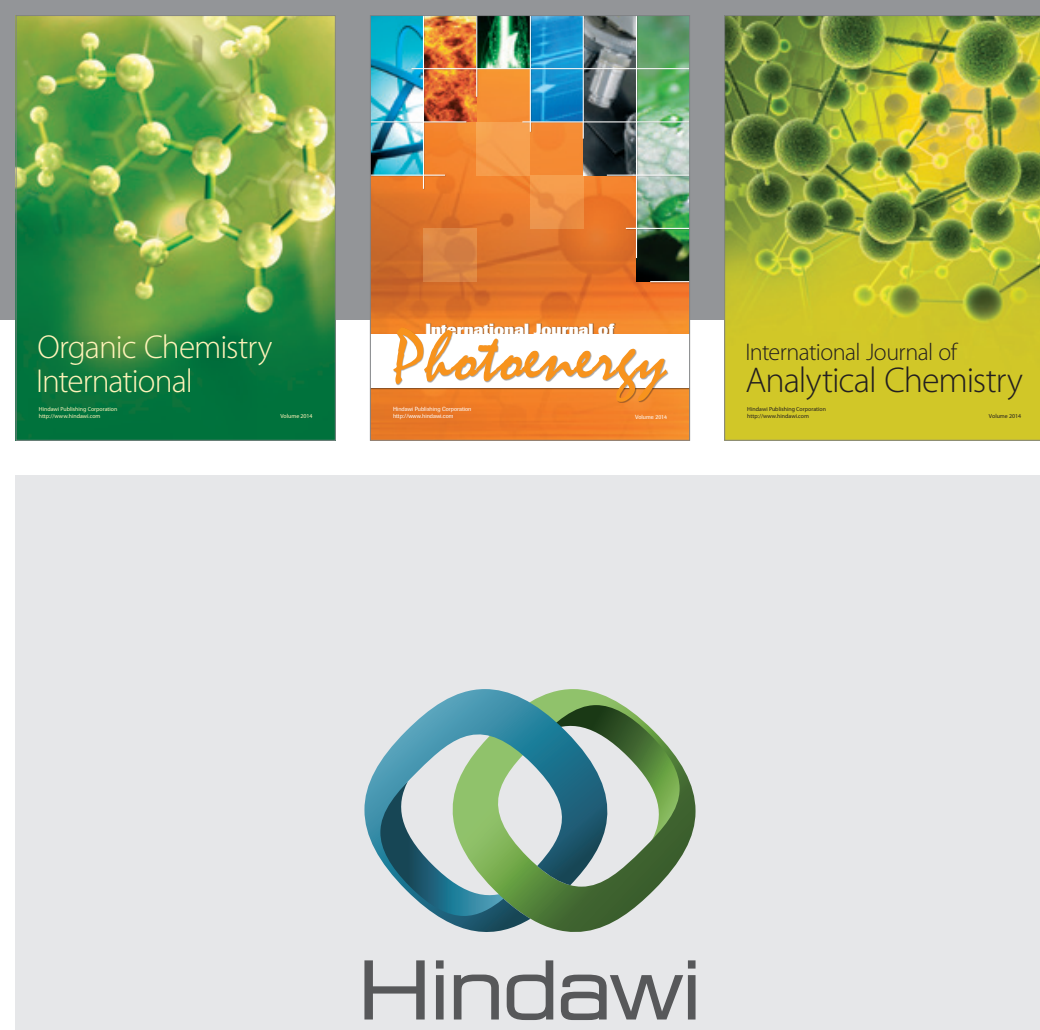

Submit your manuscripts at

http://www.hindawi.com
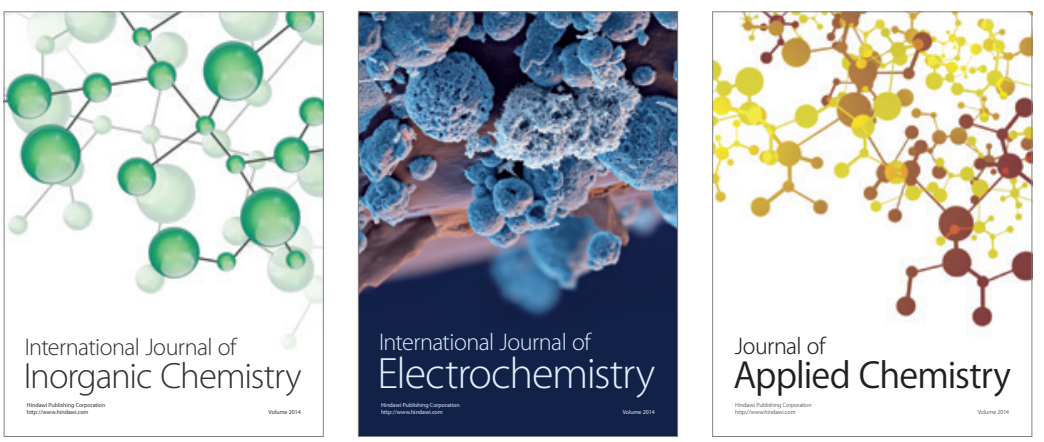

Journal of

Applied Chemistry
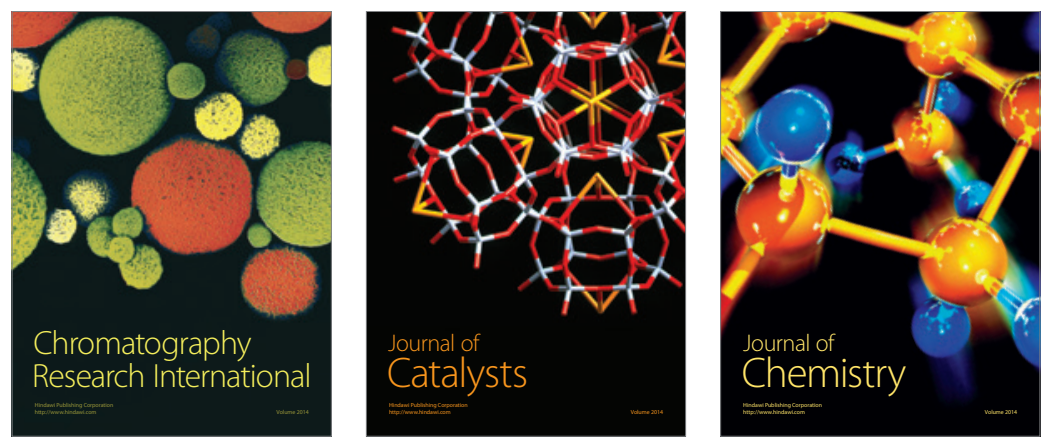
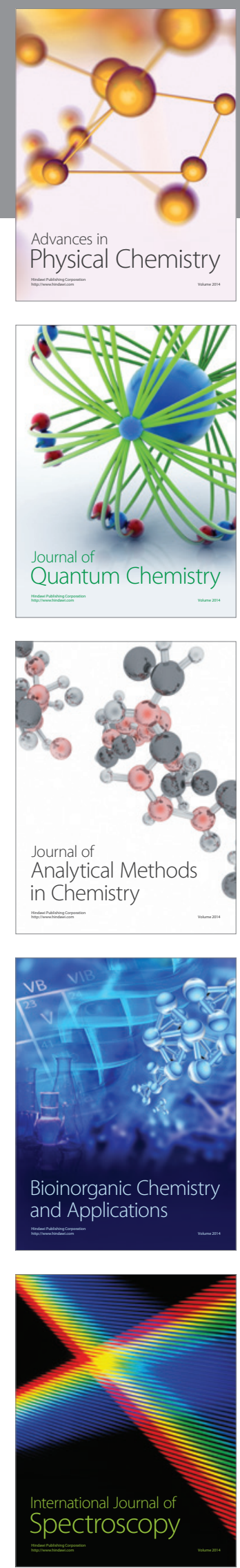